\title{
Apresentação - Apropriação da cultura escrita: a formação do leitor e autor de textos
}

\section{Presentation - Appropriation of written culture: the formation of the reader and author of texts}

https://doi.org/10.34112/2317-0972a2020V38n78p15-17

Greice Ferreira da Silva ${ }^{1}$

A SOCIEDADE CONTEMPORÂNEA SE ORGANIZA COM O ESCRITO E, nesse sentido, ler se constitui numa necessidade vital para participar dela. Desde muito cedo as crianças têm contato próximo com a leitura porque esta se encontra em toda a sociedade mediada pela presença dos escritos sociais. Pode-se dizer que a aprendizagem das crianças na escola é fundamentada na leitura, pois por meio dela se constroem as bases para o entendimento dos diversos conteúdos.

Atualmente, no Brasil, o processo de apropriação da leitura e da escrita é tema de muitas pesquisas e debates, revelando uma pujante produção acadêmica. A ênfase dos estudos no campo da alfabetização aponta a insistente busca de caminhos que permitam adensar a compreensão da complexidade desse processo, na tentativa de potencializar uma consistente atuação na escola com as crianças para o enfrentamento dos embates cotidianos e da superação dos desafios no trabalho docente.

Diante dessas considerações, o objetivo desse dossiê é apresentar e socializar investigações sobre as questões teórico-metodológicas e epistemológicas que envolvem o processo de apropriação da cultura escrita pelas crianças e a formação do leitor e do autor/escritor de textos. A intenção é promover a reflexão e discussão de aspectos nucleares que envolvem esse processo, tais como: proposições para a compreensão dos

1. Universidade Estadual de Londrina. 
atos de ler e de escrever, as diferentes dimensões da alfabetização, o papel da literatura na apropriação da linguagem escrita. Ao mesmo tempo em que exigem investigações mais aprofundadas, esses aspectos demandam avanços nas discussões que possam analisar criticamente esse fenômeno à luz das suas relações com a prática social.

O conteúdo desse dossiê se compõe de cinco artigos. O primeiro artigo desencadeador das reflexões promove uma crucial e profícua discussão sobre o ato de ler. Sobre a função dos aspectos imateriais no ato de ler: Jakubinskij, Vološinov, Bakhtin e Foucambert, de autoria de Dagoberto Buim Arena, discorre sobre o aspecto imaterial do ato de ler. Ele traz as contribuições da filosofia da linguagem e parte do conceito de massa aperceptiva, desenvolvido pelo linguista russo Jakubinskij nas duas primeiras décadas do século XX. Para tanto, apoia-se em recortes do pensamento de autores que se debruçaram sobre o conceito de massa aperceptiva, como Vološinove Bakhtin, ou de autores como Foucambert, que se aproximam desse conceito. $O$ intuito é o de perceber o seu papel central na aprendizagem dos atos culturais de ler e apontar o grau de importância que a ele atribuem reconhecidos teóricos desse campo.

O segundo artigo, intitulado $A$ brincadeira de papéis sociais e a formação de bases para a apropriação da linguagem escrita pela criança pré-escolar, de Aline Janell de Andrade Barroso Moraes e Michelle de Freitas Bissoli, trata das relações entre o brincar e o desenvolvimento da linguagem escrita com base nas contribuições da Teoria Histórico-Cultural. As autoras enfatizam o pressuposto de que o conhecimento dos professores a respeito da pré-história da escrita pode contribuir para um trabalho pedagógico mais efetivo na formação de leitores e autores, ao ressaltarem que a apropriação da cultura escrita pela criança é um processo longo e complexo que se inicia muito antes de sua entrada na escola. Elas consideram os postulados de Vigotski sobre o desenvolvimento da capacidade simbólica e o controle de conduta como condições essenciais para o desenvolvimento da capacidade de ler e escrever, capacidades essas exercitadas por diferentes atividades, especialmente o brincar de faz-de-conta.

O terceiro artigo, A apropriação da cultura escrita em crianças do ensino fundamental: um estudo com a cultura e a literatura infantil indígena, de Maria da Luz Lima Sales e Ângela Maria Franco Martins Coelho de Paiva Balça, focaliza em seu bojo a literatura infantil indígena para promover a formação de leitores, a apropriação da cultura escrita, a educação multicultural, bem como uma reflexão sobre tais temas na escola. Buscou-se por meio da pesquisa realizada a valorização da expressão literária indígena, por entender que esta proporciona ao leitor oportunidade de conhecer novos pensamentos e valores, configurando-se como veículo de conscientização 
e empatia e, ao mesmo tempo, de formação do leitor. Pretendeu-se durante esse estudo levar à escola autores e narrativas quase desconhecidos do grande público a fim de minorar a lacuna que há ainda hoje em relação à literatura infantil indígena no Brasil.

O quarto artigo, de Adriana Pastorello Buim Arena, intitulado Lobato e o pequeno leitor do século XXI, impulsiona uma reflexão sobre a linguagem, bem como sobre a fundamental importância da literatura infantil na constituição da criança leitora, ao apontar que as obras de Monteiro Lobato parecem ser abordadas superficialmente no ensino fundamental, embora sejam bastante conhecidas. A autora levanta a hipótese de que a ausência de livros de Lobato nas escolas de ensino fundamental não esteja apenas relacionada à polêmica do racismo já tanto discutida, mas também à permanente transformação da linguagem e dos modos de as pessoas interagirem com e no mundo. Instaura-se, assim, a discussão de como o processo de transformação da linguagem e os valores sociais afetam o status de uma obra em diferentes contextos históricos, sociais e culturais. Com esse objetivo, a autora se utiliza de artigos acadêmicos que discorrem sobre a natureza da linguagem, e da análise do capítulo 1 da obra Caçadas de Pedrinho, de Monteiro Lobato.

No quinto e último artigo, A formação da criança leitora por meio dos gêneros do discurso: questões metodológicas, Edith Maria Batista Ferreira e Joelma Reis Correia abordam o processo de apropriação da cultura escrita enfatizando o ensino do ato de ler no cenário escolar. As autoras analisam situações vivenciadas em sala de aula de duas turmas do $1^{\circ}$ ano do ensino fundamental de duas escolas da Rede Pública Municipal de São Luís-MA, situações que afastam ou aproximam a criança dos anos iniciais da leitura. Para tanto, entendem os gêneros enunciativos como lócus de manifestação da linguagem, por se originar nas esferas ou campos da atividade humana. Elas defendem que o ato de ler precisa ser ensinado na escola a partir dos gêneros do discurso, tendo como parâmetro seus aspectos vitais.

Os artigos aqui reunidos resultam de pesquisas de estudiosos afeitos às questões relativas à apropriação da cultura escrita e buscam ampliar e intensificar o diálogo sobre a temática. Que as ideias partilhadas possam ecoar nas muitas leituras e reverberar positivamente nas práticas escolares, numa tentativa deliberada e esperançosa de formarmos crianças leitoras e autoras que atuem e participem ativamente da sociedade.

Boa leitura! 